\title{
A Framework for Effective Implementation of Lean Production in Small and Medium-sized Enterprises
}

\author{
Amine Belhadi ${ }^{1}$ iD, Fatima Ezzahra Touriki ${ }^{2}$ iD, Said El Fezazi ${ }^{1}$ \\ ${ }^{1}$ Industrial Engineering Research Team, Higher School of Technology, Safi, Cadi Ayyad University (Morocco) \\ ${ }^{2}$ Department of Industrial Engineering, National School of Applied Sciences, Safi, Cadi Ayyad University (Morocco) \\ belhadi-9@,hotmail.fr,.f.touriki@uca.ma, selfezazi@gmail.com
}

Received: February 2016

Accepted: July 2016

\section{Abstract:}

Purpose: The present paper aims at developing an effective framework including all the components required for implementing lean production properly in Small and Medium-sized Enterprises.

Design/methodology/approach: The paper begins with the review of the main existing framework of lean implementation in order to highlight shortcomings in the literature through a lack of suitable framework for small companies. To overcome this literature gap, data of successful initiatives of lean implementation were collected based on a multiple case study approach. These initiatives has been juxtaposed in order to develop a new, practical and effective framework that includes all the components (process, tools, success factors) that are necessary to implement lean in Small and Medium-sized Enterprises.

Findings: The proposed framework presents many significant contributions: First, it provides an overcoming for the limitations of the existing frameworks by proposing for consultants, researchers and organizations an effective framework for lean implementation in SMEs. This will allow SMEs to benefit from competitive advantages gained by lean. Second, it brings together a set of the more essential and critical elements of lean implementation commonly used by SMEs and derived from the practical experiences of them in lean implementation. Finally, it highlights 
the successful experiences of small companies in implementing lean programs and then proves that lean can give relevant results even for SMEs.

Research limitations/implications: the proposed framework presents a number of limitations and still evokes extension for further researches: Although it was derived from practical experiences of SMEs, the proposed framework is not supported by practical implementation. On the other hand and even though the elements in the proposed framework are derived from the practical experiences of four SMEs, the identified elements need to be generalized and enriched by conducting a survey to identify more elements that are also commonly used in SMEs.

Practical implications: Implementing rigorously the proposed framework will help small companies' managers to improve considerably their organization's performance and benefits from lean strategies' outcomes. Researchers and practitioners in small businesses now possess an integral framework for successfully implementing lean strategies.

Originality/value: To the best knowledge of the authors, this is the first work that proposes an effective lean implementation framework believed to be easy to understund, practical and suitable for small companies. In short, this study is a real quantum leap to resolve the problematic unanswered of lean implementation in SMEs.

Keywords: lean production, framework, implementation, small to medium-sized enterprises

\section{Introduction}

Twenty-first century industry is characterized by fierce competition required by the challenges of the current highly dynamic and fast moving environment. In this scheme, organizations need to increase the effectiveness and efficiency of their operations to keep survival. To fulfill this immediate need, lean production originated in Japan in 1980, has proven a great capacity of giving the manufacturers a competitive edge by minimizing waste and improving efficiency (Kumar, Kumar, Haleem \& Gahlot, 2013). This philosophy of production combines distinctive tools, practices and strategies that can be applied to identify immensely efficient and effective production system using fewer resources to create higher quality and generate more profits (Pettersen, 2009). In fact, many companies, mostly large ones, have widely strived for lean transformation in order to keep their competitiveness in global markets (Anand \& Kodali, 2008). As a matter of fact, various literatures have documented its enormous benefits such as reduction in costs, times, defects and wastes along with improvement in quality, flexibility and overall equipment effectiveness (Bhamu \& Sangwan, 2014; Dennis, 2007; Liker \& Yu, 2000). 
Accordingly, lean implementation has become increasingly a challenge for every organization, but particularly for small and medium-sized enterprises (SMEs), which play a very tremendous role in national economies. Therefore, many of these companies have tried, even modestly, to implement lean, among which, only a very few have achieved the desired improvement (Bhamu \& Sangwan, 2014). Most of them are still unable to engage effectively lean programs and complete their lean transformation. The biggest challenge facing these companies is to know which principles, tools and practices to implement and how to effectively apply them. In the literature, countless studies have been carried out in lean, proposing various frameworks/models such as that of Åhlström (1998), Womack and Jones (2003), and Karim and Arif-Uz-Zaman (2013) but most of them are derived from the experiences of large companies, therefore they look unsuitable from the view of SMEs. Moreover, Yusof and Aspinwall (2000) approved that smaller companies cannot just imitate, in total, the approaches adopted by their large counterparts. There is therefore a real need to develop a new framework for SMEs.

In an attempt to meet the immense need to have a methodology of lean implementation believed to be suitable for SMEs and adapted to their specific characteristics, this article develops an implementation framework for lean in an effective manner. The new framework proposes a recommended set of implementation steps, tools and success factors that are derived from the successful experiences of four small sized companies and refined by the findings of the review of the current lean implementation frameworks. To fulfil the aim of this research, the following objectives were developed: (1) to review the main current frameworks and models of lean implementation, (2) to investigate the process of lean implementation in SMEs through case studies, and (3) to develop a new framework including tools and success factors for lean implementation within SMEs.

The paper is arranged as follows: After the introduction, Section 2 provides a presentation of all preliminary studies including the review of existing frameworks of lean, problem definition and research methodology. Different case studies are detailed in Section 3. Section 4 describes the framework developed with all its elements. Finally conclusions are presented with limitations of the study and recommendations for further research. 


\section{Preliminary Study}

\subsection{Review of Existing Frameworks of Lean Implementation}

This paper provides to SMEs a new framework for lean implementation that is contrary to existing frameworks, derived from their own experience and therefore more suitable to their context. Indeed, there have been numerous lean implementation initiatives proposed in the literature. However, these initiatives are derived, most often, from the experiences of large companies and do not consider the specific context of SMEs. Small firms, by virtue of their size, are constrained by a number of obstacles such as the lack of technical and managerial expertise and human resources deficiencies (Achanga, Shehab, Roy \& Nelder, 2006). Yusof and Aspinwall (2000) proved that not all improvement initiatives could be adopted by SMEs. This is because there are a set of characteristics must be satisfied by a framework or model of implantation of any improvement initiative, including Lean, for it to be considered suitable for SMEs. These characteristics are:

1. Systematic and easily understood;

2. Simple in structure;

3. Having clear links between the elements or steps outlined;

4. General enough to suit different contexts;

5. Represent a road map and a planning tool for implementation;

6. Answers "how to?" and not "what is?" the initiative approach; and

7. Implementable in SMEs.

These characteristics, referred to as 1-7, provide a basis for the review of the main existing frameworks/models of lean implementation. The objective is to check their adequacy in the context of SMEs. Note that a $(\sqrt{ })$ denotes that the framework/model satisfy the characteristic while a $(\mathrm{X})$ shows that it is not. Table 1 shows the review of the frameworks using the characteristics above.

According to Table 1, based on the characteristics cited by Yusof and Aspinwall (2000), none of the frameworks reviewed are totally adapted to SMEs.

Åhlström (1998) and Womack and Jones (2003) proposed descriptive frameworks for the implementation of Lean as definitions and sequences of implementation steps. They have based on the theoretical concept of the lean. Both frameworks are simple-structured and easy to understand. However, they suffer from various shortcomings that make them not very compatible with the structure of SMEs. First the links between their elements are insufficiently specified ( $\AA$ hlström in particular), also, they do not detail, both, "how" to deploy these principles. The same remark may be made on both models of Smeds (1994) 
and Motwani (2003). These are two simple and comprehensible models for the management of the transformation towards lean. However, they are overly general and do not provide any details about the tools to use to achieve this change. The model, that explicates tools to implement in lean program, is that of Anand and Kodali (2010). Nevertheless, this model is consisted of 65 lean practices which make it quite complicated to implement, or even be well understood, in the SMEs' environment that lack of expertise, resources and time. Contrariwise, the model of Rose, Deros and Rahman (2010) is quite simple-structured, based on SMEs characteristics and implementable with feasible lean practices. However, this model does not provide a step by step guidelines or process of implementing these practices unlike other existing models such as that of Karim and Arif Uz-Zaman (2013) and Mostafa, Dumrak and Soltan (2013). However, these two models are not designed specifically for SMEs. Moreover, they are very consumer of resources.

\begin{tabular}{|l|l|l|l|l|l|l|l|l|}
\hline Lean implementation framework & Description & 1 & 2 & 3 & 4 & 5 & 6 & 7 \\
\hline (Smeds, 1994) & $\begin{array}{l}\text { Generic framework for managing changes towards } \\
\text { lean enterprise. }\end{array}$ & $\sqrt{ }$ & $\sqrt{ }$ & $\sqrt{ }$ & $\sqrt{ }$ & $X$ & $X$ & $X$ \\
\hline (Åhlström, 1998) & $\begin{array}{l}\text { Framework for sequencing the lean production } \\
\text { principles in the implementation process }\end{array}$ & $\sqrt{ }$ & $\sqrt{ }$ & $X$ & $\sqrt{ }$ & $X$ & $X$ & $X$ \\
\hline (Womack \& Jones, 2003) & $\begin{array}{l}\text { Framework for lean definition and implementation } \\
\text { steps }\end{array}$ & $\sqrt{ }$ & $\sqrt{ }$ & $\sqrt{ }$ & $\sqrt{ }$ & $X$ & $X$ & $X$ \\
\hline (Motwani, 2003) & $\begin{array}{l}\text { Theoretical framework based on business process } \\
\text { change }\end{array}$ & $X$ & $X$ & $X$ & $\sqrt{ }$ & $X$ & $X$ & $X$ \\
\hline (Anand \& Kodali, 2010) & $\begin{array}{l}\text { Conceptual framework which consisted of 65 lean } \\
\text { practices }\end{array}$ & $X$ & $X$ & $X$ & $\sqrt{ }$ & $\sqrt{ }$ & $\sqrt{ }$ & $X$ \\
\hline (Rose et al., 2010) & $\begin{array}{l}\text { Conceptual framework for lean implementation in } \\
\text { SmEs }\end{array}$ & $\sqrt{ }$ & $\sqrt{ }$ & $X$ & $\sqrt{ }$ & $\sqrt{ }$ & $X$ & $\sqrt{ }$ \\
\hline (Karim \& Arif-Uz-Zaman, 2013) & $\begin{array}{l}\text { Effective framework for implementing lean } \\
\text { manufacturing strategies }\end{array}$ & $\sqrt{ }$ & $X$ & $\sqrt{ }$ & $\sqrt{ }$ & $\sqrt{ }$ & $\sqrt{ }$ & $X$ \\
\hline (Mostafa et al., 2013) & $\begin{array}{l}\text { Conceptual framework for lean implementation } \\
\text { containing the success factors }\end{array}$ & $\sqrt{ }$ & $X$ & $\sqrt{ }$ & $\sqrt{ }$ & $\sqrt{ }$ & $\sqrt{ }$ & $X$ \\
\hline
\end{tabular}

Table 1. Review of the main existing frameworks of lean implementation and its satisfaction of the characteristics of SMEs

\subsection{Current Research Gap and Problem Defining}

The review of the existing frameworks of lean above highlighted some shortcomings in the literature through a lack of suitable framework for SMEs. As a matter of fact, none of the frameworks proposed in the literature provide a simple and practical guidance for SMEs. Some are too generic and bet on longterm changes which do not satisfy SMEs who want often see quick results (Smeds, 1994; Åhlström, 1998; Womack \& Jones, 2003; Motwani, 2003), while others rely on the implementation of lean tools without any regard for the efficiency of actions compared to the resources consumed (Anand \& Kodali, 2010; 
Karim \& Arif-Uz-Zaman, 2013; Mostafa et al., 2013). This could cause many obstacles for the effective deployment of lean. In short, these frameworks are derived from the experiences of large companies. They are therefore unsuitable and cannot guarantee the desired results for SMEs. Subsequently, there are a real need for a new framework for lean implementation designed on the basis of the own experience of SMEs in lean implementation as presented in Figure 1.

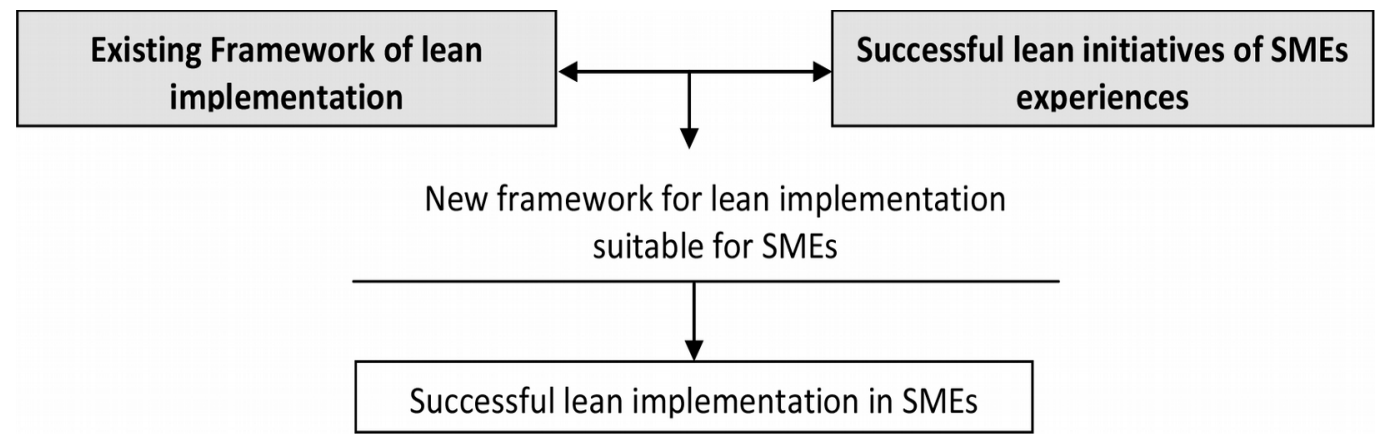

Figure 1. The need of SMEs for a suitable framework of lean implementation

As can be observed, the new framework developed must combine best practices derived from successful initiatives of lean implementation in SMEs and the finding of the review of the existing frameworks in order to overcome the limitations of these frameworks. Thus, this framework was constructed on the basis of an investigation of successful initiatives of four SMEs and perfected through the review of the existing frameworks in the literature.

\subsection{Research Methodology}

This paper aims at providing for SMEs a more suitable, practical and concise path for lean transformation. To fulfill this aim, it is well documented that case studies provide the very effective approach (Eisenhardt, 1989; Yin, 1994). This is advocated by Yin (1994) who recommended that a case study was especially appropriate when trying to answer the "how". This is perfectly useful for our case. Moreover, several researchers have adopted this methodology to design lean implementation models for different context (Nordin, Deros, Wahab \& Rahman, 2012; Karim \& Arif-Uz-Zaman, 2013). Depending on the research perspectives and the availability of data, this methodology can be applied in single- or multiple-case. Opting for multiple case studies corresponds to reproduce the experience and hence to illustrate different aspects of the studied case. This helps to corroborate the obtained results (Yin, 1994). Consequently, it was decided to pursue this methodology. All the steps of the methodology taken are shown in Figure 2. 
As was already seen, the study started with a review of a collection of the main existing frameworks of lean implementation, which were discussed briefly. This led to demonstrate the current gap in the literature that arise from a real need for a suitable methodology for SMEs that summarizes all the main components of lean implementations into a single framework. The development of such framework requires go through successful experiences of some SMEs in lean implementation. For that, the authors have used the professional networking "LinkedIn" to gather and select 30 SMEs from different sizes and types. Afterwards, a first contact is established with companies via e-mail.

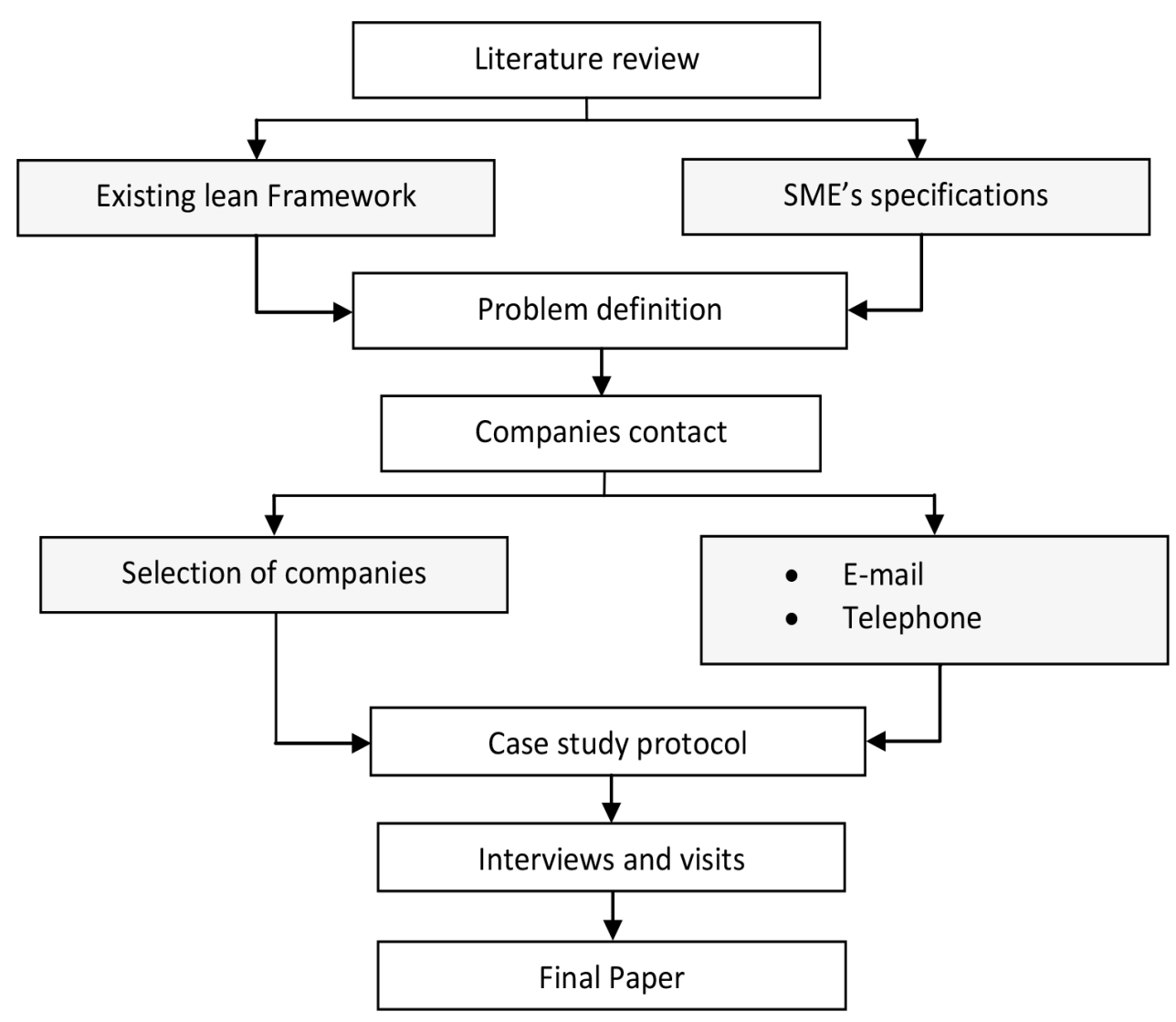

Figure 2. Research methodology

Eventually, four companies accepted to participate in the study, while the others decided to not taking part for many reasons like: "the information you demand is confidential", or "Our Company had not yet complete the lean transformation", or even they did not respond to our e-mail. Then, these were followed up by telephone calls to get the contact person who is one of the key persons responsible of lean implementation. Finally, case studies are conducted in four companies which referred to as $\mathrm{C} 1-\mathrm{C} 4$ for reasons of confidentiality. Their details are given in Table 2. 


\begin{tabular}{|c|c|r|r|c|}
\hline Company & Activity & $\begin{array}{c}\text { Number of } \\
\text { employees }\end{array}$ & Turnover & $\begin{array}{c}\text { Year of first Lean } \\
\text { implementation }\end{array}$ \\
\hline C1 & Automotive components & 180 & $£$ 38 million & 2010 \\
\hline C2 & Office furniture & 224 & $£ 42$ million & 2011 \\
\hline C3 & Metal construction & 52 & $£ 1.6$ million & 2012 \\
\hline C4 & Automobile assembly & 198 & $£ 26$ million & 2012 \\
\hline
\end{tabular}

Table 2. Main characteristics of the companies

Although the main information of the company seems quite different to the reader, an analysis of company profiles revealed that the companies selected share common characteristics:

- First point to be clarified is that all companies had less than 250 employees and less than $£, 50$ million in turnover therefore they are considered as SMEs,

- Second, all companies are operating in discrete flow, which means that the ultimate results of this study can safely be generalized to all companies in this production field,

- Finally, they have all implemented lean programs for some years.

Before beginning the interviews, a case study protocol was established grouping a set of procedures involved in data collection. This helped to minimize variation in data collected from each case and facilitate ulterior comparisons. Thus, the protocol is organized as follows:

- Company background: this part concentrates on general information about the company (activities, turnover, and number of employees...), the general context of the project of lean implementation, its motivations and achieved results,

- Unfolding of the project: during this part, the company presents the project of lean implementation including approaches undertaken, tools implemented and the different factors that lead to the success of the project.

The interviews were conducted with one of the key persons responsible of lean implementation. In the case of company $\mathrm{C} 1$, they were tow engineers "lean leaders" of the project, in company C2 the "Supply Chain Manager", in company C3 the "Production director" and in company C4 the "Process engineer". 


\section{Review of the Approaches Adopted by the SMEs Investigated}

\subsection{Case Study C1}

\section{Company background}

The first company is a French automotive supplier specializing in the acoustic environment of the vehicle. It possesses three production lines that perform three types of standard products: cushions and headrests, coverings and plastic automobile components and carpeted floor mats for the interior and trunk. The company works on a wide range of projects and it is considered as a leading provider for numerous international automobile manufacturers.

After startup in 2004, an important project of the preparation for the ramp-up was launched in order to satisfy the increasing demand of customers. The main purpose of this project was the rationalization of the supply chain while minimizing resources consumption. Therefore, it was felt that the best way is to engage a lean transformation in the organization.

The implementation of lean has covered the entire production process. The total duration of the project was 72 days with a total investment of approximately 10,500£, and an annual return of investment (ROI) of up to $10.17 \%$. Finally, the project recorded significant results such as increasing in the productive capacity for the three production lines from 108 vehicles/shift to 129 vehicles/shift, reduction in operators waiting and motion time of $30.04 \%$ and reduction in changeover time of about $45 \mathrm{mn}$. The annual gain of the project was $1,060 \AA$.

\section{Unfolding of the project}

Lean was been introduced progressively starting with the production line of cushions and headrests as pilot area. The project consisted of four major phases: preparatory phase, conceptual phase, implementation phase and generalization phase.

During the "preparatory phase", the management has appointed tow industrial engineers as "lean leaders" who have received proper training driven by a lean exert consultant for 3 days. Afterwards, the "lean leaders" have formed a multidisciplinary team containing tow process and maintenance technicians, quality controller and qualified operator. The first task of the "lean team" was to choose the first line on which the lean program will be initiated. On the basis of a "Pareto analysis", the team has chosen the production line of cushions and headrests because of its high annual volume of production (58\%), longest lead time and high number of clients' complaints (62\%). The preparatory phase was enclosed by 
setting the project objectives that was the increase of the production capacity by $20 \%$ and the reduction of the clients' complaints number by $80 \%$.

The "conceptual phase" consisted of two steps. First, the lean team established a master plan of lean deployment. This master plan contained the detail of the following steps with necessary deadlines and resources of each step. Afterwards, Key Performance Indicators have been identified for tracking the achievement of the objectives set by the management during the previous phase.

As for the "implementation phase", the team began with the establishment of the current situation map which enabled the detection of a set of abnormalities that hampering the ramp-up. Then, the team has redesigned the future situation and deducted the "Kaizen project" needed. These projects are scheduled in a planning followed up directly by the management which has committed itself to making available all necessary human and material resources for the lean team. Notice that all actions are undertaken by involving the maximum of employees and by taking advantages of their collective intelligence, experience, know-how and willingness to improve.

When preliminary results started to appear, the approach has been taken up for the second and third production lines during the "generalization phase".

\subsection{Case Study C2}

\section{Company background}

The second company has beginning its operations since 1957. Its main activity includes production and distribution of office furniture as well as design solutions for space layout. The company, situated in morocco, positions itself both as designer and producer of a range of products that are essentially: wooden and semi metallic desks, office chairs, filing cabinet, meet chairs, center service, restaurants and hotels furniture.

The competitive environment in office furniture's sector has putted the company in a very difficult situation. Thus, it encountered a number of difficulties:

- Customers complaints are increasing dramatically at about $10 \%$ per year,

- Actual delivery times are three times more than times expected,

- Facility shutdowns had risen to over $25 \%$ of the global opening time.

To deal with this situation, the company attempted throughout 2006 to implement lean practices. However, this attempt was finally failed and lean transformation was abandoned for many reasons: 
- Insufficient training on lean thinking,

- Lack of management involvement,

- Lack of vision and long term strategy,

- Simultaneous implementation of lean tools on too many machines.

Despite the earlier failure, the management has decided in 2011 to implement anew lean program and to ensure its success by securing the management support, the long-term vision and the motivation of everyone in the company.

\section{Unfolding of the project}

What distinguished the second lean implementation project compared to the earlier attempt was the structured approach which provided the general framework for the implementation of lean tools. This approach comprised three main phases: initial phase, execution phase and locking phase.

The initial phase began with the precise definition of the project objectives followed by conducting a training program animated by an expert consultant for the "lean team". The first task of this team was the choice of an adequate product to be analyzed using the product/process matrix. The initial phase enclosed by a qualitative diagnosis of the maturity level of the lean culture within the organization in order to better focus the actions during the execution phase.

The first step in the execution phase contained the upgrading of the production workshop by initiating a 5S-Housekeeping program. This was then followed by the mapping and the assessment of the current situation. The analysis of the resulting mapping gave rise to an action plan in the form of Kaizen events:

1. Control Quality through Six sigma project,

2. Flow acceleration using a set of tools: SMED, Kanban, FIFO.

After closing Kaizen projects, the team has elaborated all necessary working standards in order to capitalize on best practices and guarantee the locking of the realized improvement. These best practices were extended to all workstations. Afterwards, the approach was entirely taken up for the different products families. Currently, the lean program covers 18 from 24 families. 


\subsection{Case Study C3}

\section{Company background}

Founded in 1923, the third company is a Spanish medium sized business specializes in metal construction. Today, the company is one of the leadings metal constructors. It employs nearly 52 people including operators, officers and managers, and generates annual sales of around 1.600.000£. The company possesses two production workshops:

- Heavy-mechanical workshop (HMW) intended for the repair, refurbishing or overhaul of mechanical equipment (Gears, drive systems, trucks and other handling materials) as well as lining works (bearing),

- Precision mechanic workshop (PMW) specializes in gears cutting, manufacturing of crown gears of $5400 \mathrm{~mm}$ diameter and Spur gears and manufacturing of mechanical parts by drawing or model (shafts of $1000 \mathrm{~mm}$ diameter, Track rollers, Bearings for screw drives).

The company has a very great potential to expand its global market share in order to differentiate itself from its competitors and handle large-scale projects. Subsequently, management has recognized the need for an integral improvement project focuses on reducing both costs and delays and increasing quality level. It therefore engaged a lean program.

As a matter of fact, lean was implemented on the two workshops for 118 days with an investment of $7,500 £$. The project has allowed the company to realize a net gain of about $14,000 £$, annually.

\section{Unfolding of the project}

The company was based on a three-phase implementation approach: Training phase, Implementation phase and generalization phase.

During the first phase, a "lean leader" was appointed and a multidisciplinary team was drafted to conduct the lean project. This team was given a lean training led by an outside consultant to improve its degree of belief and culture change. Afterwards, management announced the official launch of the project and clearly set its objectives in line with the overall corporate strategy.

Shortly after startup, the lean team has identified specific improvement opportunities (Kaizen). The focus was on finding Kaizen projects that should be easy to implement with the maximum potential of gain. Therefore, the team relied heavily upon a "Cost Study" using "Cost deployment flowchart". This helped to establish a cost reduction program that encompasses two major blocks of cost reduction, first look 
unplanned shutdown and second look manufacturing nonconformities. The cost reduction program was implemented through pilot projects leaded by the "lean team" and based on lean practical toolkits:

- TPM project with the aim of reducing shutdowns costs,

- Quality control project aimed at the reduction of manufacturing nonconformities costs,

The final phase consisted of sustainability of results and best practices achieved. Meanwhile, the reduction program was extended to cover other blocks of cost reduction. Finally, the company estimated that savings of more than $12 \%$ of the total wasting costs was made since lean implementation.

\subsection{Case Study C4}

\section{Company background}

Situated in China, the fourth company was founded in 1959 and tasked with importing and assembling vehicles components CKD (Completely Knock Down). Recently, the company has set up a secondary production facility in close proximity to its main manufacturing plant. It has then increasing its stuff to 198 employees and its turnover to about 26,000,000£.

The production process of the vehicles of the company aims to assembly all imported CKD components with vehicles parts manufactured locally. This was carried out mainly in three stages: sheet metal working, paintwork and final assembly. This semi-automatic process is standard for all makes of cars assembled with a changeover while changing makes.

Since its foundation, the company has continued to gain its market share and became the leading supplier of prominent global automakers. Initially, The Company's production capacities have perfectly followed its strategy of evolution of its market. Afterwards, the market has registered an endless regression of sales that promoted the company's managers to review their strategy. In fact, the challenge became not only to increase capacities but also to synchronize supply with demand. Finally, top management made the bold decision to implement lean system. 


\section{Unfolding of the project}

At the beginning of the project, the management has clearly expressed its commitment evidenced by the elaboration of a lean policy that set all the objectives of the project. Next, the management appointed the "Supply Chain Manager" as the "Lean Leader" who was responsible for constituting a multifunctional team comprising two engineers and three technicians. This team has attended to an initial training for 7 days led by an expert lean consultant. After training, the team started with "Pareto Analysis" in order to select the initial lean perimeter. Finally, one car make that representing $32 \%$ of the annual revenue and $19 \%$ of the production volume was chosen. For this initial perimeter, the lean has established and validated with the management the master plan of lean implementation. This master plan was for 162 days with a budget of 25,000£. The first phase was ended by the formulation of Key Performance Indicators (KPI's).

Next, an upgrading program was initiated in order to create a conducive environment for the culture change. The program was consisted of two levels. In the first level a training program was conducted on lean thinking and toolkits for all the employees. This was accompanied by a wide Communication and awareness-raising. In the second level a housekeeping program was initiated to reorganize the work floor.

After the upgrading program, the team addressed the analysis of the current situation using the "cost deployment". All manufacturing costs are separated and analyzed in order to put the light on the nonvalue added activities in the process. This was followed by further improvement actions as pilot projects:

- Kanban project for the reduction of inventories and works in progress,

- TOC project (Theory of constraints) for the remove of the stoppage time,

- U-cell project for the reduction of handling distances and moving time,

- SMED project for the reduction of changeover time,

A daily results monitoring was performed with the presence of management in order to sharpen efforts, motivate the various actors and highlight their success. The main achievements of the project were the saving of about $130,000 \AA$.

These conclusive results have promoted the lean team to capitalize on best practices through a transverse project of "Knowledge Management". Furthermore, the whole approach has been taken up for the other product families. Since 2012, about $60 \%$ of standard product families have been covered by the lean system. 


\subsection{Case Studies Findings}

In this part, the results obtained and conclusions drawn from case studies are summarized in order to meet the cognitive aims of the present study.

\subsubsection{Process of Lean Implementation in SMEs}

As to the process of lean implementation, the companies in which the case studies were conducted are all relied on three-phase process. Each phase consists of a set of steps. Table 3 lists the steps perused by each company. Note that a $(\mathrm{O})$ indicates that the step was carried out by the company while a $(\mathrm{X})$ denotes that it was not.

\begin{tabular}{|c|c|c|c|c|c|}
\hline Stage & Step & $\mathrm{C} 1$ & $\mathrm{C} 2$ & C3 & $\mathrm{C} 4$ \\
\hline \multirow{7}{*}{$\begin{array}{l}\text { Pre implementation stage } \\
\text { (Preparation) }\end{array}$} & Establishment of lean policy/lean objectives & $\mathrm{O}$ & $\mathrm{O}$ & $\mathrm{O}$ & $\mathrm{O}$ \\
\hline & Establishment of lean Team & $\mathrm{O}$ & $\mathrm{O}$ & $\mathrm{O}$ & $\mathrm{O}$ \\
\hline & Training of lean team & $\mathrm{O}$ & $\mathrm{O}$ & $\mathrm{O}$ & $\mathrm{O}$ \\
\hline & Definition of the initial perimeter & $\mathrm{O}$ & $\mathrm{O}$ & $\mathrm{X}$ & $\mathrm{O}$ \\
\hline & Establishment of master plan of lean deployment & $\mathrm{O}$ & $\mathrm{X}$ & $\mathrm{X}$ & $\mathrm{O}$ \\
\hline & Definition of lean indicators & $\mathrm{O}$ & $\mathrm{O}$ & $\mathrm{O}$ & $\mathrm{O}$ \\
\hline & Diagnostic of lean culture level & $\mathrm{X}$ & $\mathrm{O}$ & $\mathrm{X}$ & $\mathrm{O}$ \\
\hline \multirow{4}{*}{$\begin{array}{l}\text { Implementation stage } \\
\text { (Execution) }\end{array}$} & Upgrading workforce and workstations & $\mathrm{X}$ & $\mathrm{O}$ & $\mathrm{X}$ & $\mathrm{O}$ \\
\hline & Model and analyse the current situation & $\mathrm{O}$ & $\mathrm{O}$ & $\mathrm{O}$ & $\mathrm{O}$ \\
\hline & Identification of opportunities & $\mathrm{O}$ & $\mathrm{O}$ & $\mathrm{O}$ & $\mathrm{O}$ \\
\hline & Implementation of pilot projects & $\mathrm{O}$ & $\mathrm{O}$ & $\mathrm{O}$ & $\mathrm{O}$ \\
\hline \multirow{4}{*}{$\begin{array}{l}\text { Post implementation phase } \\
\text { (Generalization) }\end{array}$} & Results monitoring & $\mathrm{O}$ & $\mathrm{X}$ & $\mathrm{O}$ & $\mathrm{O}$ \\
\hline & Capitalization and Standardization of lean practices & $\mathrm{X}$ & $\mathrm{O}$ & $\mathrm{O}$ & $\mathrm{O}$ \\
\hline & Generalization of actions & $\mathrm{X}$ & $\mathrm{O}$ & $\mathrm{O}$ & $\mathrm{X}$ \\
\hline & Extension of lean perimeter & $\mathrm{O}$ & $\mathrm{O}$ & $\mathrm{X}$ & $\mathrm{O}$ \\
\hline
\end{tabular}

Table 3. Process of lean implementation in SMEs reviewed

As can be seen, all the case companies have clearly defined the lean objectives and indicators during the preparation phase. Moreover, all the companies have also carried out a delimitation of the initial perimeter except the third company that possesses only one value chain. On the other hand, a good practice requires to be capitalized from the companies C1 and C4 is the establishment of the master plan of lean implementation. 
The execution phase is almost similar for all the companies with the exception of the important step of "Upgrading workforce and workstations" which is ignored by the companies C1 and C3.

As to the generalization phase, four steps are capitalized from the companies. These are "results monitoring, "Capitalization and Standardization of lean practices", "Generalization of actions" and "Extension of lean perimeter".

\subsubsection{Lean Tools Implemented in SMEs}

This part capitalizes on the set of tools implemented by the companies in which the case study was performed. Table 4 summarizes tools implemented by companies during each phase.

\begin{tabular}{|c|c|c|c|c|c|}
\hline Stage & Step & $\mathrm{C} 1$ & $\mathrm{C} 2$ & C3 & $\mathrm{C} 4$ \\
\hline \multirow{6}{*}{$\begin{array}{l}\text { Pre implementation stage } \\
\text { (Preparation) }\end{array}$} & Lean policy/ lean objectives & $\mathrm{O}$ & $\mathrm{O}$ & $\mathrm{X}$ & $\mathrm{O}$ \\
\hline & Multifunctional Team & $\mathrm{O}$ & $\mathrm{O}$ & $\mathrm{O}$ & $\mathrm{O}$ \\
\hline & Training & $\mathrm{O}$ & $\mathrm{O}$ & $\mathrm{O}$ & $\mathrm{O}$ \\
\hline & Product/ Process Matrix & $\mathrm{X}$ & $\mathrm{O}$ & $\mathrm{X}$ & $\mathrm{X}$ \\
\hline & Pareto Analysis & $\mathrm{O}$ & $\mathrm{X}$ & $\mathrm{X}$ & $\mathrm{O}$ \\
\hline & Master plan & $\mathrm{O}$ & $\mathrm{X}$ & $\mathrm{X}$ & $\mathrm{O}$ \\
\hline \multirow{11}{*}{$\begin{array}{l}\text { Implementation stage } \\
\text { (Execution) }\end{array}$} & 5S/ Housekeeping & $\mathrm{X}$ & $\mathrm{O}$ & $\mathrm{X}$ & $\mathrm{O}$ \\
\hline & Value Stream Mapping (VSM) & $\mathrm{O}$ & $\mathrm{O}$ & $\mathrm{X}$ & $\mathrm{X}$ \\
\hline & Cost Deployment & $\mathrm{X}$ & $\mathrm{X}$ & $\mathrm{O}$ & $\mathrm{O}$ \\
\hline & Kaizen & $\mathrm{O}$ & $\mathrm{X}$ & $\mathrm{X}$ & $\mathrm{X}$ \\
\hline & Statistical Process Control (SPC) & $\mathrm{X}$ & $\mathrm{X}$ & $\mathrm{O}$ & $\mathrm{X}$ \\
\hline & Six Sigma & $\mathrm{X}$ & $\mathrm{O}$ & $\mathrm{X}$ & $\mathrm{X}$ \\
\hline & Total Productive Maintenance (TPM) & $\mathrm{X}$ & $\mathrm{X}$ & $\mathrm{O}$ & $\mathrm{X}$ \\
\hline & Theory of Constraints (TOC) & $\mathrm{X}$ & $\mathrm{X}$ & $\mathrm{X}$ & $\mathrm{O}$ \\
\hline & Kanban & $\mathrm{X}$ & $\mathrm{O}$ & $\mathrm{X}$ & $\mathrm{O}$ \\
\hline & FIFO & $\mathrm{X}$ & $\mathrm{O}$ & $\mathrm{X}$ & $\mathrm{X}$ \\
\hline & U cell & $\mathrm{X}$ & $\mathrm{X}$ & $\mathrm{X}$ & $\mathrm{O}$ \\
\hline \multirow{3}{*}{$\begin{array}{l}\text { Post implementation phase } \\
\text { (Generalization) }\end{array}$} & Scoreboard & $\mathrm{O}$ & $\mathrm{X}$ & $\mathrm{O}$ & $\mathrm{O}$ \\
\hline & Work Standards & $\mathrm{X}$ & $\mathrm{O}$ & $\mathrm{X}$ & $\mathrm{O}$ \\
\hline & Knowledge Management & $\mathrm{X}$ & $\mathrm{X}$ & $\mathrm{X}$ & $\mathrm{O}$ \\
\hline
\end{tabular}

Table 4. Lean tools implemented in SMEs

It is clear that during all the steps of the first phase, all the case companies have used almost the same lean toolkits. The only difference is that companies C1 and C4 have used "Pareto analysis" to define the initial 
perimeter while C2 and C3 have used the "product/Process Matrix". Similarly, during the second phase, two approaches for analyzing the current situation are distinguished. Indeed, companies C1 and C2 have based on a "Time Study" using the VSM whiles companies C3 and C4 have relied on a "Cost study" via Cost Deployment. Moreover, each company has suggested a different set of specific tools to be implemented in order to achieve the lean objectives depending on the identified opportunities. Finally, Scoreboard, Work Standards and Knowledge Management have been implemented during the last phase.

\subsubsection{Critical Success Factors of Lean Implementation in SMEs}

Equally primordial to this study is also the identification of critical success factors leading to a successful implementation of lean within SMEs environment. The identified critical success factors should constitute an insight for decision-making in the proposed framework. These factors are summarized in Table 5.

\begin{tabular}{|c|c|c|c|c|c|}
\hline Stage & Step & C1 & $\mathrm{C} 2$ & $\mathrm{C} 3$ & $\mathbf{C} 4$ \\
\hline \multirow{7}{*}{$\begin{array}{l}\text { Pre implementation stage } \\
\text { (Preparation) }\end{array}$} & Management commitment and support & $\mathrm{O}$ & $\mathrm{O}$ & $\mathrm{O}$ & $\mathrm{O}$ \\
\hline & Alignment to the global strategy of the company & $\mathrm{X}$ & $\mathrm{X}$ & $\mathrm{O}$ & $\mathrm{X}$ \\
\hline & Long term vision & $\mathrm{X}$ & $\mathrm{O}$ & $\mathrm{X}$ & $\mathrm{X}$ \\
\hline & Proper methodology of implementation & $\mathrm{X}$ & $\mathrm{O}$ & $\mathrm{X}$ & $\mathrm{X}$ \\
\hline & Training by lean expert & $\mathrm{O}$ & $\mathrm{O}$ & $\mathrm{O}$ & $\mathrm{O}$ \\
\hline & Proper selection of lean perimeter & $\mathrm{O}$ & $\mathrm{O}$ & $\mathrm{X}$ & $\mathrm{O}$ \\
\hline & Proper planning before implementation & $\mathrm{O}$ & $\mathrm{X}$ & $\mathrm{X}$ & $\mathrm{O}$ \\
\hline \multirow{4}{*}{$\begin{array}{l}\text { Implementation stage } \\
\text { (Execution) }\end{array}$} & Earlier culture change & $\mathrm{X}$ & $\mathrm{X}$ & $\mathrm{O}$ & $\mathrm{X}$ \\
\hline & Improvement with small pilot projects & $\mathrm{O}$ & $\mathrm{O}$ & $\mathrm{O}$ & $\mathrm{O}$ \\
\hline & Time and resources allocation & $\mathrm{O}$ & $\mathrm{O}$ & $\mathrm{X}$ & $\mathrm{O}$ \\
\hline & All employees' involvement & $\mathrm{O}$ & $\mathrm{X}$ & $\mathrm{X}$ & $\mathrm{O}$ \\
\hline \multirow{2}{*}{$\begin{array}{l}\text { Post implementation phase } \\
\text { (Generalization) }\end{array}$} & Performance measurement & $\mathrm{O}$ & $\mathrm{O}$ & $\mathrm{X}$ & $\mathrm{O}$ \\
\hline & Standardization and capitalization of best practices & $\mathrm{X}$ & $\mathrm{O}$ & $\mathrm{X}$ & $\mathrm{O}$ \\
\hline
\end{tabular}

Table 5. Critical success factors for a successful lean implementation in SMEs

Obtained data regarding critical success factors shows that:

During the first phase, all the companies were agreed that factors such as "Management commitment and support" and "Training by lean expert" are vitally important. Elsewhere, factors like "Alignment to the global strategy of the company", "Long term vision", "Proper methodology of implementation", "Proper selection of lean perimeter" and "Proper planning before implementation were highly highlighted by some of them. 
To ensure the success of the execution phase, case companies were all based on "Improvement with pilot projects". This has served to minimize risks, focus efforts and motivate the various actors. Other factors like "Time and resources allocation", "Earlier culture change" and especially "All employees' involvement" are also crucial.

Eventually, "Performance measurement" and "Standardization of best practices" were largely mentioned by companies as critical factors to the success of the generalization phase.

\section{Proposed Framework for Lean Implementation in SMEs}

The study of successful lean initiatives within SMEs presented above revealed plenty of elements (implementation process, tools and success factors) to be capitalized as an integral framework of lean implementation. This framework, contrary to existing models, is directly derived from the own experience of SMEs and thus considers their characteristics and specifies. Figure 3 presents the proposed framework. Step by step presentation of the framework is given in the following sections.

\subsection{Pre Implementation Phase}

Successful lean implementation relies heavily on the efficient "starting" of the implementation process. This will certainly require the company to ensure that all necessary foundations are taken place to enable a successful and sustainable lean implementation.

First of all, management must begin to show leadership and demonstrate that it is committed to the project by elaborating the lean policy and setting up lean objectives. Furthermore, lean objectives must be aligning with the strategic global policy of the organization. Then, the management is responsible for the establishment of "Lean Team". As a small business, the lean team should not contain many individuals; however, it must be a multifunctional team. The next step is the training of the lean team. This training should be conducted by a lean expert consultant to provide an initial boost for the introduction of lean culture within the team. The first task of the team is the delimitation of the perimeter of action by choosing the top priority value stream. This can be performed using the product/process matrix or simply by Pareto analysis. The proper selection of the initial perimeter of action is crucial to focus resources and maximize gains. Once the initial perimeter is selected, the team has to develop a master plan of lean implementation. This master plan should include both a schedule and a budget. The last step in the reimplementation phase is the measurement of the current situation using lean indicators. This consists of defining some performance indicators derived from the lean objectives set at the start. Once 
the lean indicators are defined, an initial measure of these indicators should be done in order to define the current state of the performance of the organization.

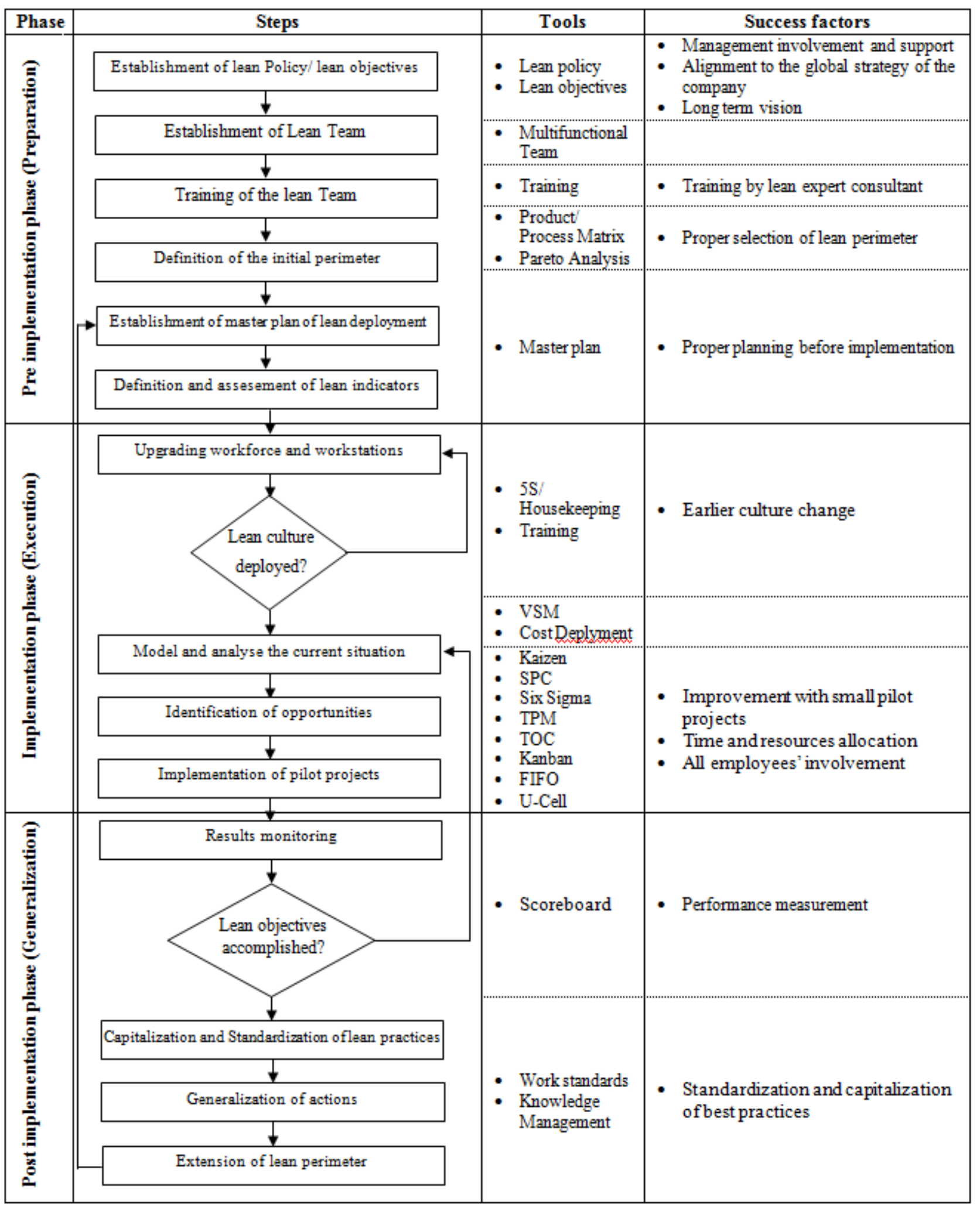

Figure 3. Proposed lean implementation framework in SMEs 


\subsection{Implementation Phase (Execution)}

The implementation phase focuses on performance improvement at all levels of the organization. This phase begins with a "warming up" step in with the lean team takes care on upgrading workforce and organizing workstations to enable the deployment of other lean practices. First, the lean team needs to educate people and train them in lean practices and tools in order to get workforce acquainted with lean and prepare them for change. Afterwards, teams are oriented to the shop floor in order to build the sense of ownership and responsibility necessary for the improvement. The first effective practice is a strong $5 \mathrm{~S}$ program that is qualified by several researchers as the easiest, less resources consumer and the most beneficial initiative during a lean journey (Lee, 2004). At the end of this step, a cultural change of people must occur. The next step in the implementation phase is to map and analyze the current process status. This can be done through a "Time study" relying on the Value Stream Mapping" or a "Cost study" via the methodology of "Cost Deployment". This step leads to identify opportunities of improvement where there is the maximum potential of performance. Once these opportunities are identified, the next step of the lean journey is to select and implement lean tools. These tools must be implemented in form of pilot project in order to ensure that any expansion of lean implementation is based on the accuracy, effectiveness and efficiency (Mostafa et al., 2013). Notice that all employees' involvement is widely recommended for the proper implementation of lean projects (Pont, Furlan \& Vinelli, 2008). This aimed at motivating them and increasing their responsibilities and ownership of actions.

\subsection{Post Implementation Phase (Generalization)}

Post implementation phase plays a critical role in completing lean implementation project and ensuring continuous improvement. First, the company needs to measure the progress it is making toward their goals (Puvanasvaran, Megat, Hong Razali \& Magid, 2010) relying on scoreboard that contains lean KPI's identified previously. Once the lean objectives are achieved, best ways to complete tasks should be capitalized, standardized and shared. This step is paramount because it allows locking in the gains obtained in the execution phase. Afterwards, lean team must attacks another perimeter starting with establishment of new master plan for lean implementation. 


\subsection{Features of the Proposed Framework of Lean Implementation in SMEs}

In this article, a framework for lean implementation in SMEs is proposed and described above. This framework is presented as a set of simplified theoretical cornerstones and practical guidelines to perform lean strategies implementation and adoption in SMEs. The proposed framework is compared with the existing lean implementation frameworks and it was founded that the proposed framework possesses all characteristics that increase its chance of success. Following are the features of the proposed framework which set it compliant with the characteristics of Yusof and Aspinwall (2000) that has been used previously in the second section.

- The proposed framework encompasses common known principles, tools and success factors. Moreover, it is self-explanatory and easy to understand for SMEs. Accordingly, the first characteristic "Systematic and easily understood" is widely satisfied,

- The framework has a quite simple structure, which coordinates phases and steps of implementation, tools to apply in each step and success factors during each step. Consequently, it is clear that the framework satisfies the second characteristic "Simple in structure",

- The links between different elements of the framework (steps, tools and success factors) are clearly distinguished because of its logical and sequential representation. Therefore, the satisfaction of the characteristic of "Having clear links between the elements or steps outlined" is evident,

- The proposed framework combines the successful experience of different types and sizes of SMEs (automatic/ manual process, Medium/ small size ...etc.). Hence, SMEs of all types (of discrete process) and sizes have every opportunity to implement successfully this framework. That is why the criterion of "General enough to suit different contexts" is highly met,

- The logic behind this proposed framework is to define a structured sequence of elements and guidelines (steps, tools and success factors). Thus, the satisfaction of the criterion of "Represent a road map and a planning tool for implementation" is obvious,

- The main purpose of the framework is to propose an effective response for the issue of how can SMEs introduce lean effectively in their production process. Then, it is clear that it answers "how to?" and not "what is?"

- All the elements of the proposed framework is already implemented by the SMEs in which case studies are performed. Moreover, the framework contains guidelines, tools and practices affirmed to be suitable for SMEs by several authors (Matt \& Rauch, 2013; Zhou, 2012; Real, Pralus, Pillet \& Guizzi, 2007). For these reasons, the proposed roadmap meets the criterion of "Implementable". 
In sum, the proposed framework is suitable and applicable to SMEs in different types, since it provides practical methodology that summarizes the main elements (steps, tools and success factors) for the introduction of lean production in a very specific type of organizations such as SMEs.

\section{Conclusion}

This paper started with a claim that large companies worldwide were always the most privileged to adopt many advanced enhancement approaches including lean implementation and then enjoy advantages resulted by implementation of these approaches in their organizations compared to SMEs. One of the reasons for not implementing lean extensively in SMEs is the lack of an understandable and effective framework suitable for SMEs and bringing together all lean components and guidelines even though researchers around the globe have documented several frameworks.

A review of a collection of the main existing frameworks of lean implementation demonstrated that none of these frameworks reported in the literature are perfectly suitable to be implemented in SMEs. This gap in the literature demands development of an effective framework of implementing lean in SMEs taking the specificities of these companies into consideration and grouping all essential lean components. This is achieved through case studies conducted in four small and medium sized enterprises operating in different areas and having different characteristics of production processes. The outcome was a more meaningful framework that groups all the requirements and guidelines for lean implementation (implementation process, tools and success factors). The proposed framework has a simple structure including three phases to accomplish the lean implementation. Afterwards, this framework is confirmed as suitable to SMEs because of its satisfaction of a set of criteria recommended by several authors.

Although it is constructed based on the individual experiences of four SMEs, the proposed framework presents many significant contributions:

- Firstly, it provides an overcoming for the limitations of the existing frameworks by proposing for consultants, researchers and organizations an effective framework for lean implementation in SMEs that allows SMEs to benefit from competitive advantages gained by lean,

- Secondly, it brings together a set of the more essential and critical elements of lean implementation commonly used by SMEs and derived from the practical experiences of them in lean implementation, 
- Finally, it highlights the successful experiences of small companies in implementing lean programs and then it proves that lean can give relevant results even for SMEs.

- On the other hand, the proposed framework presents a number of limitations and still evokes extension for further researches:

- Although it was derived from practical experiences of SMEs, the proposed framework is not supported by practical implementation,

- Even though the elements in the proposed framework from the practical experiences of four SMEs operating in discrete flow, It can be tested for further researches in continuous flow to confirm its applicability in this field.

In a nutshell, this work is a real quantum leap to resolve the problematic unanswered of lean implementation in SMEs. However, and to further improve its fulfillment the authors recommend a validation of the proposed framework by carrying out an implementation in a typical organization. Moreover, the framework could be enriching by studying other experiences as case studies or even surveys.

\section{References}

Achanga, P., Shehab, E., Roy, R., \& Nelder, G. (2006). Critical success factors for lean implementation within SMEs. Journal of Manufacturing Technology Management, 17(4), 460-471.

http://dx.doi.org/10.1108/17410380610662889

Åhlström. (1998). Sequences in the Implementation of Lean Production. European Management Journal, 16(3), 327-334. http://dx.doi.org/10.1016/S0263-2373(98)00009-7

Anand, G., \& Kodali, R. (2008). Benchmarking the benchmarking models. Benchmarking: An International Journal, 15(3), 257-291. http://dx.doi.org/10.1108/14635770810876593

Anand, G., \& Kodali, R. (2010). Analysis of lean manufacturing frameworks. Journal of Advanced Manufacturing Systems, 1(9), 1-30. http://dx.doi.org/10.1142/S0219686710001776

Bhamu, J., \& Sangwan, K.S. (2014). Lean manufacturing: literature review and research issues. International Journal of Operations \& Production Management, 34(7), 876-940. http://dx.doi.org/10.1108/IJOPM-08-2012-0315

Dennis, P. (2007). Lean production simplified (2nd ed.). New York: Productivity Press. 
Eisenhardt, K. (1989). Building theories from case study research. Academy of Management Review, 14, 532-550.

Karim, A., \& Arif-Uz-Zaman, K. (2013). A methodology for effective implementation of lean strategies and its performance evaluation in manufacturing organizations. Business Process Management Journal, 19(1), 169-196. http://dx.doi.org/10.1108/14637151311294912

Kumar, N., Kumar, S., Haleem, A., \& Gahlot, P. (2013). Implementing Lean Manufacturing System: ISM Approach. Journal of Industrial Engineering and Management, 6(4), 996-1012. http://dx.doi.org/10.3926/jiem.508

Lee, C.Y. (2004). TQM in small manufacturers: an exploratory study in China. International Journal of Quality \& Reliability Management, 21(2), 175-197. http://dx.doi.org/10.1108/02656710410516970

Liker, J.K., \& Yu, Y.-C. (2000). Japanese automakers, US suppliers and supply-chain superiority. Sloan Management Review, 42(1), 81-93.

Matt, D., \& Rauch, E. (2013). Implementation of Lean Production in small sized Enterprises. 8th CIRP Conference on Intelligent Computation in Manufacturing Engineering, 12, 420-425.

http://dx.doi.org/10.1016/j.procir.2013.09.072

Mostafa, S., Dumrak, J., \& Soltan, H. (2013). A framework for lean manufacturing implementation. Production \& Manufacturing Research: An Open Access Journal, 1, 44-64.

http://dx.doi.org/10.1080/21693277.2013.862159

Motwani, J. (2003). A business process change framework for examining lean manufacturing: a case study. Industrial Management \& Data Systems, 103(5), 339-346. http://dx.doi.org/10.1108/02635570310477398

Nordin, N., Deros, B.M., Wahab, D.A., \& Rahman, M.N.A. (2012). A framework for organisational change management in lean manufacturing implementation. International Journal of Services and Operations Management, 12(1), 101-117. http://dx.doi.org/10.1504/IJSOM.2012.046676

Pettersen, J. (2009). Defining lean production: some conceptual and practical issues. The TQM Journal, 21(2), 127-142. http://dx.doi.org/10.1108/17542730910938137

Pont, G.D., Furlan, A., \& Vinelli, A. (2008). Interrelationships among lean bundles and their effects on operational performance. Operations Management Research, 1(2), 150-158. http://dx.doi.org/10.1007/s12063008-0010-2

Puvanasvaran, P., Megat, H., Hong, T.S., Razali, M.M., \& Magid, H.A. (2010). Lean process management implementation through enhanced problem solving capabilities. Journal of Industrial Engineering and Management, 3(3), 447-493. http://dx.doi.org/10.3926/jiem.2010.v3n3.p447-493 
Real, R., Pralus, M., Pillet, M., \& Guizzi, L. (2007). A study of supporting programs for small and medium enterprises: a first stage going to "Lean". Proceedings of the 2007 IEEE IEEM.

http://dx.doi.org/10.1109/ieem.2007.4419243

Rose, A., Deros, B., \& Rahman, M. (2010). Development of framework for lean manufacturing implementation in SMEs. The 11th Asia Pacific Industrial Engineering and Management Systems Conference.

Smeds, R. (1994). Managing Change towards Lean Enterprises. International Journal of Operations \& Production Management, 14(3), 66-82. http://dx.doi.org/10.1108/01443579410058531

Womack, J., \& Jones, D. (2003). Lean Thinking: Banish Waste And Create Wealth In Your Corporation (2nd ed.). Simon \& Schuster UK Ltd.

Yin, R. (1994). Case study research, design and methods (2nd ed.). California: Sage Publications.

Yusof, S.M., \& Aspinwall, E. (2000). A conceptual framework for TQM implementation for SMEs. The TQM Magazine, 12(1), 31-36. http://dx.doi.org/10.1108/09544780010287131

Zhou, B. (2012). Lean principles, practices, and impacts: a study on small and medium-sized enterprises (SMEs). Annals of Operations Research, 1-18.

Journal of Industrial Engineering and Management, 2016 (www.jiem.org)

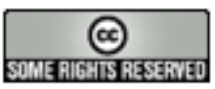

Article's contents are provided on an Attribution-Non Commercial 3.0 Creative commons license. Readers are allowed to copy, distribute and communicate article's contents, provided the author's and Journal of Industrial Engineering and Management's names are included. It must not be used for commercial purposes. To see the complete license contents, please visit http://creativecommons.org/licenses/by-nc/3.0/. 